\title{
Proliferation marker securin identifies favourable outcome in invasive ductal breast cancer
}

\author{
K Talvinen ${ }^{*, 1}$, J Tuikkala ${ }^{2}$, O Nevalainen ${ }^{2}$, A Rantanen ${ }^{3}$, P Hirsimäki', J Sundström' and P Kronqvist' \\ 'Department of Pathology, Turku University Hospital, University of Turku, Kiinamyllynkatu 10, FIN-20520 Turku, Finland; ${ }^{2}$ Department of Information \\ Technology, University of Turku, FIN-200 I 4 Turku, Finland; ${ }^{3}$ Department of Surgical Hospital, Turku University Hospital, PL 28, FIN-2070I Turku, Finland
}

\begin{abstract}
We introduce a new proliferation marker, securin (pituitary tumour-transforming I (PTTGI)), analysed in invasive ductal breast carcinomas by cDNA microarrays and immunohistochemistry. In cDNA microarray of a total of 4000 probes of genes, securin was revealed with a significant change in expression among the several proliferation-related genes studied. The value of securin as a proliferation marker was verified immunohistochemically $(n=44)$ in invasive ductal breast cancer. In follow-up analyses of the sample of patients, the prognostic value of securin was compared with the established markers of breast cancer proliferation, Ki-67 and mitotic activity index (MAl). Our results of a small sample of patients suggest that low securin expression identifies a distinct subgroup of more favourable outcome among patients with high Ki-67 immunoexpression or high MAl. In univariate analysis of Cox's regression, I0-unit increment of securin immunopositivity was associated with a 2.3-fold overall risk of death due to breast cancer and a 7.1 -fold risk of death due to breast cancer in the sample of patients stratified according to the cutoff points of 10 and $20 \%$ of securin immunopositivity. We suggest that securin immunostaining is a promising and clinically applicable proliferation marker. The finding urges further prognostic studies with a large sample of patients.

British Journal of Cancer (2008) 99, 335-340. doi: I0.1038/sj.bjc.6604475 www.bjcancer.com
\end{abstract}

Published online I July 2008

(c) 2008 Cancer Research UK

Keywords: securin; breast cancer; cDNA microarray; immunohistochemistry; proliferation; prognosis

In breast tumour biology, deregulated proliferation is one of the most important features predicting malignant behaviour (Desmedt and Sotiriou, 2006). The prognostic power of mitotic activity and traditional proliferation markers, such as standardised mitotic counts and Ki-67, is established in pathological practice. To benefit individual breast cancer patients, the potential of the traditional prognostic features could still be intensified by additional methods (Olivotto et al, 1999; Michels et al, 2003; Oestreicher et al, 2004; Warwick et al, 2004; Jalava et al, 2006).

We introduce a new proliferation marker, securin (pituitary tumour-transforming 1 (PTTG1)), which was revealed in cDNA microarray analysis with a significant change in expression among several proliferation-related genes studied in invasive ductal breast cancer. Immunohistochemically, the value of securin as a proliferation marker was confirmed among the established proliferation markers of breast cancer. The results emphasise the potential of securin as a prognostic feature to add information in identifying a specific subgroup of more favourable outcome in invasive ductal breast cancer.

*Correspondence: Dr K Talvinen; E-mail: kattal@utu.fi Revised 7 April 2008; accepted 21 May 2008; published online I July 2008

\section{MATERIALS AND METHODS}

\section{Patient material}

The cDNA microarray analysis was performed on 10 patients and immunohistochemical analysis on 2 patient groups, a total of 44 patients, diagnosed in 1996 and 2004 with invasive ductal breast cancer in Turku University Hospital, Turku, Finland (Table 1). The patients were treated with mastectomy with either sentinel lymph node examination or axillary evacuation, and adjuvant treatment with anti-oestrogen, trastuzumab or cytostatic drugs depending on patient's age, hormone receptor status and CISH-confirmed Her2/ neu oncogene amplification. All patients participated in regular clinical follow-up during first 5 postoperative years or until the end point of the study. Complete clinical and follow-up data starting from date of diagnosis were available from all patients. Causes of death were verified from autopsy reports, death certificates and patient files from the Finnish Cancer Registry.

\section{Methods}

cDNA microarray analysis In cDNA microarray analysis, special emphasis was placed on the quality of tissue material. Samples were obtained fresh from the operation theatre during surgery, carefully prepared from fat and connective tissue, fresh frozen in liquid nitrogen and stored at $-70^{\circ} \mathrm{C}$ within $30 \mathrm{~min}$ after surgical removal. Normal tissue was obtained from benign breast tissue outside the tumour from five patients to prepare a reference pool for cDNA microarray analysis. The diagnosis of all samples was 
Table I Clinicopathological characteristics of patient material in cDNA microarrays and immunohistochemistry $(\mathrm{IHC})$

\begin{tabular}{|c|c|c|}
\hline & Microarray $(n=10)$ & IHC $(n=44)$ \\
\hline \multicolumn{3}{|l|}{ Age at diagnosis (years) } \\
\hline Mean (range) & $69(27-86)$ & $63(27-87)$ \\
\hline \multicolumn{3}{|l|}{ Tumour diameter $(\mathrm{cm})$} \\
\hline Mean (s.d.) & $3.2(1.45)$ & $2.6(1.68)$ \\
\hline \multicolumn{3}{|l|}{ Histological grade (\%) } \\
\hline I & 20 & 18 \\
\hline$\|$ & 30 & 41 \\
\hline III & 50 & 41 \\
\hline \multicolumn{3}{|c|}{ Axillary nodal status (\%) } \\
\hline Node- & 30 & 54 \\
\hline Node+ & 70 & 46 \\
\hline \multicolumn{3}{|l|}{ Follow-up time } \\
\hline Mean (range) & $\begin{array}{l}2 \text { years and } 6 \text { months } \\
\text { (10 months to } 3 \text { years } \\
\text { and } 5 \text { months) }\end{array}$ & $\begin{array}{l}4 \text { years and I month } \\
\text { (I0 months to } 9 \text { years } \\
\text { and II months) }\end{array}$ \\
\hline \multicolumn{3}{|l|}{$\begin{array}{l}\text { Causes of death } \\
\text { during follow-up }\end{array}$} \\
\hline Breast cancer (\%) & 20 & 14 \\
\hline Other (\%) & 10 & 7 \\
\hline
\end{tabular}

verified from a consecutive histological slide. Microarray included approximately 4000 probes of genes with proven or suspected roles in human cancer (Turku Centre for Biotechnology, University of Turku and Abo Akademi University, Turku, Finland). Total RNA isolation, purification, labelling and microarray hybridisation have been described previously (Talvinen et al, 2006). Briefly, $21.5 \mu \mathrm{g}$ of tumour and reference RNAs was fluorescently labelled (CyDye, Amersham Biosciences, Buckinghamshire, England) with Cy5 and Cy3, respectively, during cDNA synthesis using an oligo(dT) primer (Amersham Biosciences) and Superscript II reverse transcriptase (Gibco BRL Life Technologies, Rockville, MD, USA). Hybridisation was performed in a humidified chamber under LifterSlips (Erie Scientific Company, Portsmouth, NH, USA) overnight at $65^{\circ} \mathrm{C}$. Each sample was hybridised once. The sequences of the relevant up- and downregulated genes were verified (Turku Centre for Biotechnology).

Immunostainings Immunostainings of securin and Ki-67 were performed on 4 - $\mu \mathrm{m}$-thick formalin-fixed and paraffin-embedded sections according to a standard procedure. For securin immunostainings, antigen retrieval was performed by repeated microwave heating in $10 \mathrm{~mm}$ sodium citrate buffer $(\mathrm{pH} 6)$, with monoclonal antibody applied manually at a concentration of $1: 20$ (clone DCS280, ab3305, Abcam, Cambridge, UK), and detection was performed by biotin-avidin reaction (Vectastain $\mathrm{ABC}$ reagent, Vector Laboratories, Burlingame, CA, USA) with diaminobenzidine as chromogen (Sigma, St Louis, MO, USA). Automated immunostaining machine TechMate $500^{+}$was used for Ki-67 (clone MIB-1, M 7240, DakoCytomation, Glostrup, Denmark, concentration $1: 100)$ with the peroxidase/diaminobenzidine multilink detection kit (DakoCytomation).

Mitotic counts Mitotic counts were determined as mitotic activity index (MAI) (number of mitoses per 10 high-power fields (HPFs), $450 \mu \mathrm{m}$ in diameter) according to the original publication by Baak et al (1985).
Evaluation of securin and Ki-67 immunoreactivity, and MAI Evaluation of securin and Ki-67 immunoreactivity, and MAI was performed on whole carcinoma sections based on the observed and reported (Ogbagabriel et al, 2005) focal nature of proliferation in tumour tissue. Securin and Ki-67 immunopositivities were determined by the fraction (\%) of positively stained tumour cells and securin also by the intensity of staining ( 0 , no staining; 1 , weakly stained; 2 , moderately stained; 3 , strongly stained) at the areas of most pronounced staining, usually at the most cellular, infiltrating border of the tumour. Analysis of Ki-67 positivity was based on cutoff points at 10 and $20 \%$ of cancer cells (Ki-67 $<10 \%$, $10 \% \leqslant \mathrm{Ki}-67 \leqslant 20 \%$ and $\mathrm{Ki}-67>20 \%$ ) adopted from clinical practice and based on research on breast cancer samples from Finland and other countries (Kronqvist et al, 2004; de Azambuja et al, 2007; Railo et al, 2007). The same cutoff points were applied for securin immunohistochemistry. Also the cutoff points for MAI were set at 10 and 20 mitoses in $10 \mathrm{HPFs}$ based on the original work of Baak et al (1985), the established guidelines of breast cancer grading (Elston and Ellis, 1991; Tavassoli and Devilee, 2003) and our previous results on Finnish patients (Kronqvist et al, 2000). The quality of interpretations of immunohistochemistry and MAI was verified as intra- and interobserver reproducibilities in repeated evaluations by a single observer or two independent observers by light microscopy without knowledge of the patients' clinical data.

Statistical analysis Statistical analysis of cDNA microarray experiments was performed as described previously (Talvinen et al, 2006). For each sample, the expression ratio between the study case and reference pool was determined for each transcript on the microarray. The expression ratios were $\log 2$-transformed and intensity-normalised with the locally weighted scatter plot smoothing (LOWESS; Yang et al, 2002). There were three technical replicates for each transcript on the array. The quality of each spot was determined visually and the data were preprocessed by calculating the signal over the whole data so that only spots with acceptable quality were taken into account. When there were three proper spots, the median of the replicates was used to calculate the expression ratio of the transcript. In case of two proper spots, the mean was used, and in case of only one proper spot the value was used as such. If no proper spot was found, then the transcript was marked as missing for the sample under study. Only transcripts with more than 3 non-missing signal values among the 10 samples were subjected to statistical analyses. For each transcript, the preprocessed log-ratios were compared to zero with the onesample Student's $t$-test. A transcript was considered upregulated if its mean expression ratio was larger than 0.5 and the $P$-value of the $t$-test was less than 0.05 . Similarly, a transcript was considered downregulated if its mean expression ratio was less than -0.5 and the $P$-value was less than 0.05 . The resulting gene lists were examined for biological information in the context of Gene Ontology by using the GoMiner program package (Zeeberg et al, 2003).

Intraobserver $(\mathrm{PK})$ and interobserver reproducibilities of immunohistochemical evaluations of securin and Ki-67 (PK and $\mathrm{PH}$ ) and evaluation of MAI (PK and IS) described the consistency of repeated assessments by a single observer or a pair of independent observers. They were expressed as intraclass correlation coefficients (ICCs) and weighted kappa coefficients $\left(\kappa_{\mathrm{w}}\right)$ based on cross-tabulations according to the chosen cutoff points. The same statistical analyses were applied for intermethod reproducibilities, and comparisons of the results for securin $v s$ MAI, securin vs Ki-67 and MAI vs Ki-67 were expressed with the help of scatter plots.

Prognostic associations between proliferation markers and survival in breast cancer patients were studied using survival analysis. The cumulative percentages for survival were estimated using the Kaplan-Meier technique and the differences in 
cumulative percentages between categories were tested using the log-rank test. Proliferation markers were analysed also with the Cox regression model as continuous and categorised variables. Differences were quantified by hazard ratios (HRs) and $95 \%$ confidence intervals (95\% CIs). The HRs describe the risk of death due to breast cancer associated with values of each studied proliferation marker above the cutoff point as compared with values below the cutoff point. $P$-values less than 0.05 were considered as statistically significant. All statistical computations were performed with SAS statistical package (SAS Institute, release 8.2.2001, Cary, NC, USA).

\section{RESULTS}

cDNA microarray analysis revealed a total of 131 transcripts upregulated and 256 transcripts downregulated in our sample of invasive breast cancers, corresponding to 119 and 224 up- and downregulated genes, respectively. These represented several significantly deregulated gene groups encoding proteins participating in DNA replication, regulation of cell proliferation, protein biosynthesis, superoxide dismutase activity and cytokine production. We concentrated on proliferation-related genes, among which securin showed clear deregulation and the most promising clinical applications with a consistent immunohistochemical expression pattern (Figure 1).

In immunohistochemical analysis, the average fraction of securin-positive cells was $10.9 \%$ (range 1.5-34.0) and that of Ki-67-positive cells $32.4 \%$ (range 4.0-80.0). Average MAI was 28.0 mitoses per $10 \mathrm{HPFs}$ (range 2-141 mitoses per $10 \mathrm{HPFs}$ ). Consistency of evaluations as expressed in intra- and interobserver reproducibilities of each proliferation marker is summarised in Table 2 . In our analysis, the intermethod reproducibility between

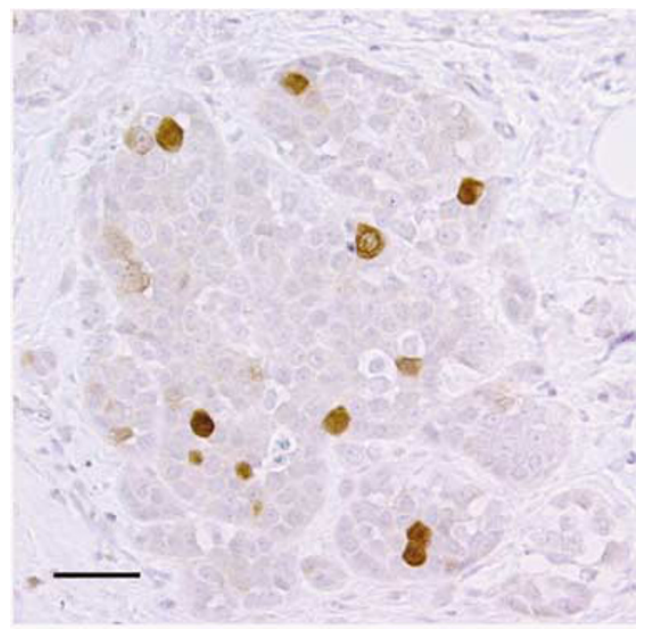

Figure I Securin immunohistochemistry in invasive ductal breast cancer. The bar represents $50 \mu \mathrm{m}$.

Table 2 Intra- and interobserver reproducibilities of securin and Ki-67 immunohistochemistry, and MAI

\begin{tabular}{|c|c|c|c|c|c|c|}
\hline & \multicolumn{2}{|c|}{ Securin } & \multicolumn{2}{|c|}{ Ki67 } & \multicolumn{2}{|c|}{ MAI } \\
\hline & ICC & $\boldsymbol{\kappa}_{\mathrm{w}}$ & ICC & $\boldsymbol{\kappa}_{\mathrm{w}}$ & ICC & $\kappa_{\mathrm{w}}$ \\
\hline $\begin{array}{l}\text { Intraobserver } \\
\text { Interobserver }\end{array}$ & $\begin{array}{l}0.8972 \\
0.5169\end{array}$ & $\begin{array}{l}0.7579 \\
0.3763\end{array}$ & $\begin{array}{l}0.9577 \\
0.9286\end{array}$ & $\begin{array}{l}0.7035 \\
0.6633\end{array}$ & $\begin{array}{l}0.9168 \\
0.9402\end{array}$ & $\begin{array}{l}0.7632 \\
0.7484\end{array}$ \\
\hline
\end{tabular}

$\mathrm{MAI}=$ mitotic activity index. The interpretations are expressed as intraclass correlation coefficients (ICC) and weighted kappa coefficients $\left(\kappa_{\mathrm{w}}\right)$.
MAI and Ki-67 was moderately high (ICC 0.5527, $\kappa_{\mathrm{w}}$ 0.2592; Figure 2A). Interpretations of proliferative activity, however, differed considerably between securin and MAI (ICC 0.1582, $\kappa_{\mathrm{w}}$ 0.1899; Figure 2B), and between securin and Ki-67 (ICC $-0.2180, \kappa_{\mathrm{w}} 0.0619$; Figure $2 \mathrm{C}$ ). In a detailed analysis, securin and Ki-67 resulted in $75 \%$ of cases differently allocated into groups of low, intermediate and high proliferation. Securin and MAI, in turn, allocated $64 \%$ of cases into different proliferation groups. In our analysis, the lowest consistency between observed proliferation rates was found among cases with low $(<10 \%)$ securin expression
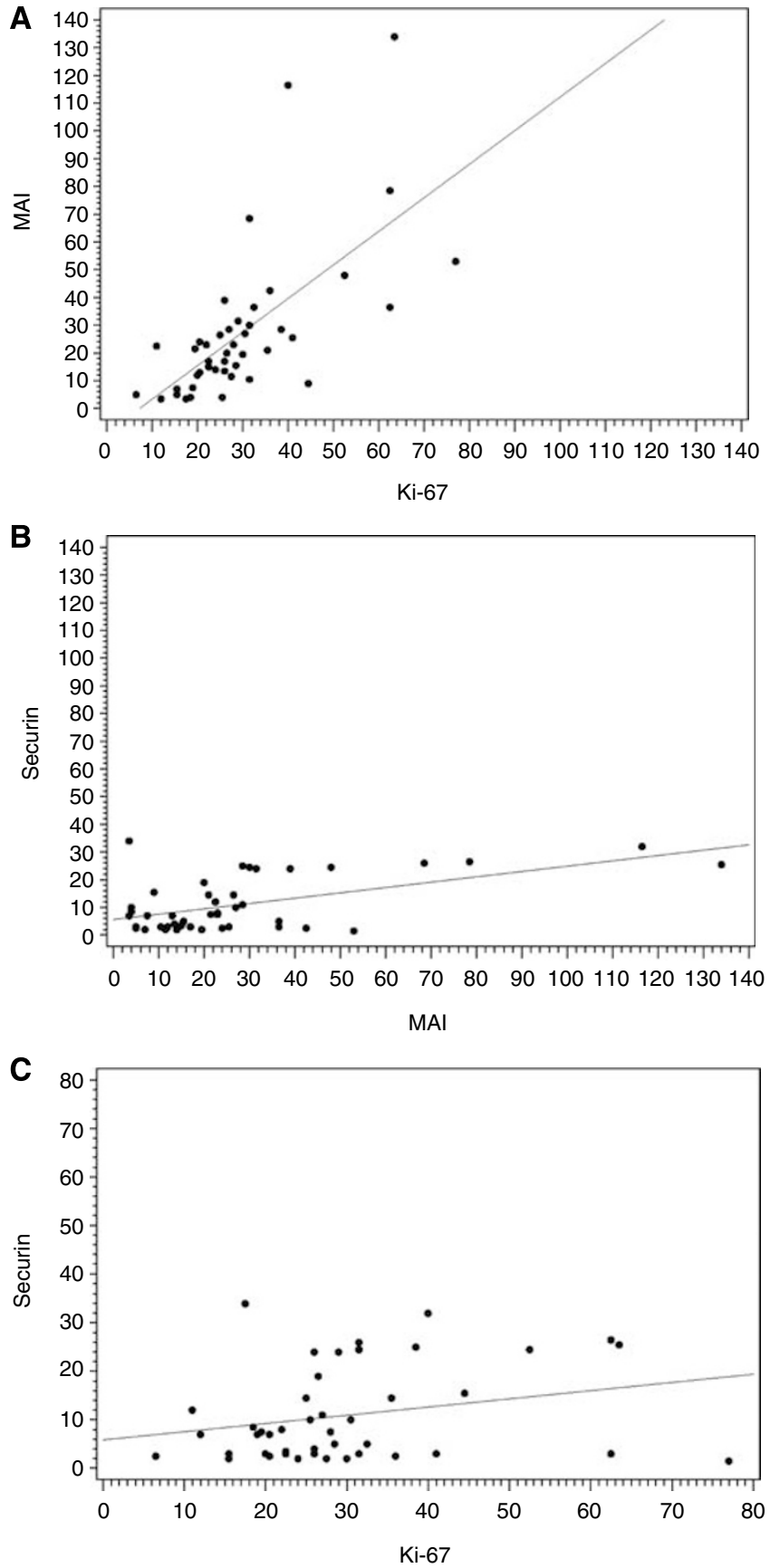

Figure 2 (A-C) Scatter plots with regression lines demonstrate differences in intermethod consistency between MAl and Ki-67 immunohistochemistry (A), securin immunohistochemistry and MAI (B), and securin and Ki-67 immunohistochemistry (C) for invasive ductal breast cancer cases $(n=44)$. 
Table 3 Univariate analysis of Cox's regression performed on 44 cases of invasive ductal breast cancer for securin and Ki-67 immunohistochemistry, and MAI

\begin{tabular}{lccc}
\hline & $\boldsymbol{P}$ & $\mathbf{9 5 \%} \mathbf{C l}$ & $\mathbf{H R}$ \\
\hline Securin & 0.0218 & $1.1-4.6$ & 2.3 \\
Ki-67 & 0.1581 & $0.9-2.1$ & 1.4 \\
MAl & 0.0227 & $1.0-1.5$ & 1.3 \\
\hline
\end{tabular}

MAI = mitotic activity index. The table summarizes $P$-values with $95 \%$ confidence intervals $(95 \% \mathrm{Cl})$ and hazard ratios (HR) of overall breast cancer death.

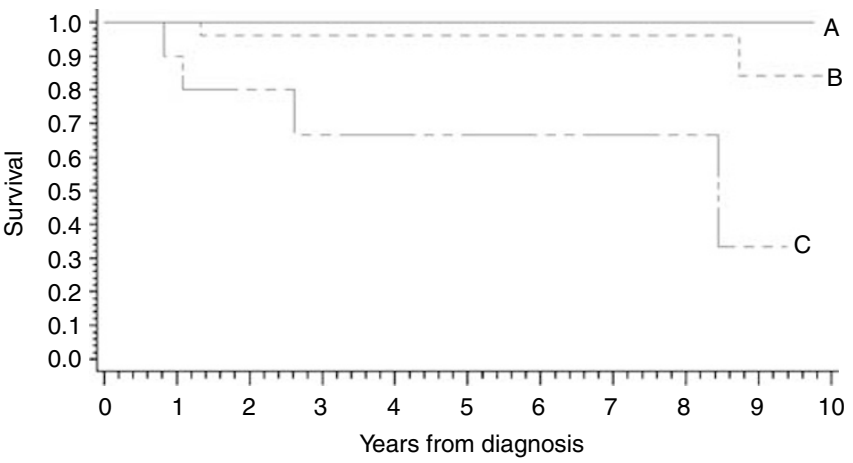

Figure 3 Kaplan-Meier curves of securin immunohistochemistry distinguish patients with low ( $<10 \%$ securin immunopositivity), intermediate $(10-20 \%$ securin immunopositivity) and high ( $>20 \%$ securin immunopositivity) risk of death due to breast cancer $(n=44)(P=0.0 \mathrm{I}$ I2).

and intermediate or high $(\geqslant 10 \%) \mathrm{Ki}-67$ expression (57\% of cases), and low $(<10 \%)$ securin expression and intermediate or high $(\geqslant 10 \%)$ MAI ( $45 \%$ of cases). Including the evaluation of the intensity of securin staining in the analysis did not improve statistical associations.

The results of univariate analysis of Cox's regression with HRs of overall risk of death due to breast cancer are summarised in Table 3 and show statistically significant prognostic value for securin immunohistochemistry and MAI (HRs 2.3 and 1.3, respectively). In our sample, only securin immunohistochemistry demonstrated statistically significant prognostic stratification of patients according to cutoff points of 10 and $20 \%$ of breast cancer cells. Among the proliferation markers studied, the highest outcome advantage was associated with securin immunopositivity (HR 7.1, $P=0.0270,95 \%$ CI $1.3-40.1$, securin $>20$ vs $<10 \%$ ). In our sample, only securin immunohistochemistry showed statistically significant prognostic value in Kaplan-Meier survival curves $(P=0.0112)$ (Figure 3$)$.

\section{DISCUSSION}

Securin is a regulatory protein that plays a central role in DNA repair, p53/TP53 pathway and chromosome stability (Jallepalli et al, 2001; Romero et al, 2001; Bernal et al, 2002). Its expression and localisation are cell cycle-dependent (Yu et al, 2000). Human cDNA homologous to rat oncoprotein Pttg was first identified by Dominguez et al (1998). It was soon discovered to be highly expressed in several carcinoma cell lines and various human tumours where its abundance was considered as a molecular marker for aggressive disease (Zhang et al, 1999). In human tumours, high securin expression has been related to increased cell proliferation and angiogenic phenotype (Kakar, 1998; Ishikawa et al, 2001).
Prognostic associations of securin have been reported in gliomas, and in hepatocellular, thyroid and esophageal carcinomas (Shibata et al, 2002; Fujii et al, 2006; Genkai et al, 2006). We have previously described securin expression in a set of genes aberrantly expressed in colorectal carcinoma as compared to paired control samples from normal mucosa (Talvinen et al, 2006) where securin expression was upregulated both at mRNA and protein levels. The role of securin in breast carcinoma is not thoroughly studied. Solbach et al (2004) published an initial observation on securin mRNA overexpression in association with lymph node involvement and tumour recurrence. In concordance with our present findings, Ogbagabriel et al (2005) have reported securin immunohistochemistry in 55 invasive ductal carcinomas and detected a statistically significant correlation with metastatic disease, especially in brain metastases. The paper by Ogbagabriel and co-workers did not analyse associations between securin and other known proliferation markers.

In the cDNA microarray performed, several proliferationassociated genes were markedly deregulated in invasive ductal breast carcinomas (Table 4). According to the magnitude of expression change, the most significantly deregulated proliferation-associated genes were topoisomerase DNA II alpha (TOP2A), securin and insulin-like growth factor 2 (somatomedin A (IGF2)). The prognostic and therapeutic applications of TOP2A and IGF2 have been extensively studied at tissue mRNA and protein levels (Sandri et al, 1996; Sachdev and Yee, 2001; Koren et al, 2004). The observed significant prognostic value of both TOP2A and IGF2 in our sample supports the reliability of the performed analyses and urges further evaluation of the prognostic value of securin in invasive breast cancer.

Based on our results, securin provides a potential proliferation marker of invasive ductal breast cancer. Comparisons of proliferation markers indicated that securin immunohistochemistry resulted in a different stratification of breast cancer cases, especially identifying patients with a more favourable prognosis than the established proliferation markers MAI and Ki-67. In our sample, a 10-unit increment of securin immunopositivity was associated with a 2.3 -fold overall risk of death due to breast cancer $(P=0.0218)$ and a 7.1 -fold risk for patients with securin immunopositivity above $20 \%$ compared to below $10 \%$ $(P=0.0270)$. Further analyses on larger samples of patients are needed but the present results suggest that securin is a potential proliferation marker that could in clinical pathology add to the information of the traditional prognosticators of invasive ductal breast cancer.

The major shortcomings of the present work are the experimental cDNA microarray methodology and the small sample size with relatively short follow-up time. However, the present results confirm and strengthen the previously published experiences on securin expression in breast cancer (Ogbagabriel et al, 2005). To compensate for the small number of patients, we have emphasised the quality of the study material by selecting patients with invasive ductal carcinomas verified by histology, and up-to date diagnostics and follow-up from the era of mammographic screening. In reproducibility analyses between observers and methods, securin performed acceptably although consistencies in evalutions of securin immunohistochemistry were not excellent as for the established methods, MAI and Ki-67. A further point of dispute could be that, in view of recent publications, MAI is optimal in prognostication of node-negative breast cancer of patients under 55 years (Louwman et al, 2006; Baak et al, 2007). At the moment, we are in the process of expanding our experience on securin immunohistochemistry of invasive and in situ carcinomas in a larger sample of patients including menopausal and nodal status.

In conclusion, we introduce a new proliferation marker, securin, which on the basis of biological, immunohistochemical and clinical data is a promising prognosticator in invasive ductal breast cancer along with the traditional proliferation markers. 
Deregulated cell proliferation-related transcripts in invasive ductal breast cancer

\begin{tabular}{|c|c|c|c|}
\hline Fold change & Type & Accession(s) & Description \\
\hline $2.3 ; 2.5$ & Down & N54596; N54596 & Insulin-like growth factor 2 \\
\hline 2.2 & Down & T53298 & Insulin-like growth factor binding protein 7 \\
\hline 2.1 & Down & T61948 & FBJ murine osteosarcoma viral oncogene homolog B \\
\hline 2.1 & Down & $\mathrm{H} 39192$ & Mitogen-activated protein kinase 7 \\
\hline 2.0 & Up & AA443982 & Protein phosphatase I, catalytic subunit, alpha isoform \\
\hline 1.9 & Up & AA3978I3 & CDC28 protein kinase 2 \\
\hline 1.9 & Down & AA424584 & Latent transforming growth factor beta binding protein 2 \\
\hline 1.8 & Down & AA455254 & Dual specificity phosphatase 6 \\
\hline 1.7 & Up & AA4577I0 & Polymerase (DNA-directed), delta 4 \\
\hline 1.7 & Down & AA630376 & Notch (Drosophila) homolog 2 \\
\hline 1.7 & Down & AA633993 & CDCIO (cell division cycle I0, S. cerevisiae, homolog) \\
\hline 1.5 & Up & N27I59 & Inhibin, beta A (activin A, activin AB alpha polypeptide) \\
\hline 1.5 & Up & AA40I479 & Cyclin-dependent kinase 5 \\
\hline 1.5 & Up & W9500I & Cell division cycle $25 \mathrm{C}$ \\
\hline 1.5 & Down & AA428365 & Retinoblastoma-binding protein 4 \\
\hline 1.5 & Down & AA490213 & Transducer of ERBB2, I \\
\hline 1.5 & Down & AA490473 & Protein phosphatase 2 (formerly 2A), catalytic subunit, beta isoform \\
\hline 1.5 & Down & AA45632I & Insulin-like growth factor I \\
\hline 1.4 & & $\mathrm{H} 20743$ & Cell division cycle 34 \\
\hline 1.4 & Down & AA598836 & Cullin 4A \\
\hline
\end{tabular}

The table includes accession numbers, type of expression change and average fold change of analysed samples. When two probes were on array, both accession numbers with corresponding fold changes have been mentioned.

\section{ACKNOWLEDGEMENTS}

We thank Mr Tero Aittokallio from the Department of Information Technology, Mrs Sinikka Kollanus from the Department of Pathology, Mr Hans Helenius and Mrs Saija Hurme from the Department of Biostatistics, and Turku Centre for Biotechnology,

\section{REFERENCES}

Baak JP, van Diest PJ, Voorhorst FJ, van der Wall E, Beex LV, Vermorken JB, Janssen EA, Gudlaugsson E, other collaborators of the Multicenter Morphometric Mammary Carcinoma Project (MMMCP) (2007) The prognostic value of proliferation in lymph-node-negative breast cancer patients is age dependent. Eur J Cancer 43: 527-535

Baak JPA, van Dop H, Kurver PHJ, Hermans J (1985) The value of morphometry to classic prognosticators in breast cancer. Cancer 56: $374-382$

Bernal JA, Luna R, Espina A, Lazaro I, Ramos-Morales F, Romero F, Arias C, Silva A, Tortolero M, Pintor-Toro JA (2002) Human securin interacts with p53 and modulates p53-mediated transcriptional activity and apoptosis. Nat Genet 32: 306-311

de Azambuja E, Cardoso F, de Castro G, Colozza M, Mano MS, Durbecq V, Sotiriou C, Larsimont D, Piccart-Gebhart MJ, Paesmans M (2007) Ki-67 as a prognostic marker in early breast cancer: a meta-analysis of published studies involving 12155 patients. Br J Cancer 96: 1504-1513

Desmedt C, Sotiriou C (2006) Proliferation: the most prominent predictor of clinical outcome in breast cancer. Cell Cycle 5: 2198-2202

Dominguez A, Ramos-Morales F, Romero F, Rios RM, Dreyfus F, Tortolero M, Pintor-Toro JA (1998) hpttg, a human homologue of rat pttg, is overexpressed in hematopoietic neoplasms. Evidence for a transcriptional activation function of hPTTG. Oncogene 17: 2187-2193

Elston CW, Ellis IO (1991) Pathological prognostic factors in breast cancer. I. The value of histological grade in breast cancer:
University of Turku, for technical assistance. This study was supported by Turku University Central Hospital, Cancer Society of South-Western Finland, and Finnish Society of Histotechnology. The study has approval from the Ethical Committee of Turku University Hospital. Each investigated specimen was included in the study only after a written consent of the patient. experience from a large study with long-term follow-up. Histopathology 19: $403-410$

Fujii T, Nomoto S, Koshikawa K, Yatabe Y, Teshigawara O, Mori T, Inoue S, Takeda S, Nakao A (2006) Overexpression of pituitary tumor transforming gene 1 in HCC is associated with angiogenesis and poor prognosis. Hepatology 43: 1267-1275

Genkai N, Homma J, Sano M, Tanaka R, Yamanaka R (2006) Increased expression of pituitary tumor-transforming gene (PTTG)-1 is correlated with poor prognosis in glioma patients. Oncol Rep 15: $1569-1574$

Ishikawa H, Heaney AP, Yu R, Horwitz GA, Melmed S (2001) Human pituitary tumor-transforming gene induces angiogenesis. J Clin Endocr Metab 86: $867-874$

Jalava P, Kuopio T, Juntti-Patinen L, Kotkansalo T, Kronqvist P, Collan Y (2006) Ki67 immunohistochemistry: a valuable marker in prognostication but with a risk of misclassification: proliferation subgroups formed based on Ki67 immunoreactivity and standardized mitotic index. Histopathology 48: 674-682

Jallepalli PV, Waizenegger IC, Bunz F, Langer S, Speicher MR, Peters J-M, Kinzler KW, Vogelstein B, Lengauer C (2001) Securin is required for chromosomal stability in human cells. Cell 105: $445-457$

Kakar S (1998) Assignment of the human tumor transforming gene TUTR1 to chromosome band 5q35.1 by fluorescence in situ hybridization. Cytogenet Cell Genet 83: 93-95 
Koren R, Rath-Wolfson L, Ram E, Itzhac OB, Schachter B, Klein B, Gal R, Dreznik Z (2004) Prognostic value of topoisomerase II in female breast cancer. Oncol Rep 12: 915 -919

Kronqvist P, Kuopio T, Collan Y (2000) Quantitative thresholds for mitotic counts in histologic grading: confirmation in nonfrozen samples of invasive ductal breast cancer. Ann Diagn Pathol 4: 65-70

Kronqvist P, Kuopio T, Nykänen M, Helenius H, Anttinen J, Klemi P (2004) Predicting aggressive outcome in T1N0M0 breast cancer. $\mathrm{Br}$ J Cancer 91: $277-281$

Louwman WJ, van Beek MW, Schapers RF, Nolthenius-Puylaert MB, van Diest PJ, Roumen RM, Coebergh JW (2006) Long-term survival of T1 and T2 lymph node-negative breast cancer patients according to Mitotic Activity Index: a population-based study. Int J Cancer 118: 2310-2314

Michels JJ, Duigou F, Marnay J, Henry-Amar M, Delozier T, Denoux Y, Chasle J (2003) Flow cytometry and quantitative immunohistochemical study of cell cycle regulation proteins in invasive breast carcinoma: prognostic significance. Cancer 97: 1376-1386

Oestreicher N, White E, Malone KE, Porter PL (2004) Hormonal factors and breast tumor proliferation: do factors that affect cancer risk also affect tumor growth? Breast Cancer Res Treat 85: 133-142

Ogbagabriel S, Fernando M, Waldman FM, Bose S, Heaney AP (2005) Securin is overexpressed in breast cancer. Mod Pathol 18: 985-990

Olivotto IA, Mates D, Kan L, Fung J, Samant R, Burhenne LJ (1999) Prognosis, treatment, and recurrence of breast cancer for women attending or not attending the Screening Mammography Program of British Columbia. Breast Cancer Res Treat 54: 73-81

Railo M, Lundin J, Haglund C, von Smitten K, Nordling S (2007) Ki-67, ER receptors, ploidy, and $S$ phase as long-term prognostic factors in $\mathrm{T} 1$ node-negative breast cancer. Tumour Biol 28: 45-51

Romero F, Multon MC, Ramos-Morales F, Domínguez A, Bernal JA, PintorToro JA, Tortolero M (2001) Human securin, hPTTG, is associated with $\mathrm{Ku}$ heterodimer, the regulatory subunit of the DNA-dependent protein kinase. Nucleic Acids Res 29: $1300-1307$

Sachdev D, Yee D (2001) The IGF system and breast cancer. Endocr Relat Cancer 8: 197-209
Sandri MI, Hochhauser D, Ayton P, Camplejohn RC, Whitehouse R, Turley H, Gatter K, Hickson ID, Harris AL (1996) Differential expression of the topoisomerase II alpha and beta genes in human breast cancers. $\mathrm{Br}$ J Cancer 73: $1518-1524$

Shibata Y, Haruki N, Kuwabara Y, Nishiwaki T, Kato J, Shinoda N, Sato A, Kimura M, Koyama H, Toyama T, Ishiguro H, Kudo J, Terashita Y, Konishi S, Fujii Y (2002) Expression of PTTG (pituitary tumor transforming gene) in esophageal cancer. Jpn J Clin Oncol 32: 233-237

Solbach C, Roller M, Fellbaum C, Nicoletti M, Kaufman M (2004) PTTG mRNA expression in primary breast cancer: a prognostic marker for lymph node invasion and tumor recurrence. Breast 13: 80-81

Talvinen K, Tuikkala J, Grönroos J, Huhtinen H, Kronqvist P, Aittokallio T, Nevalainen O, Hiekkanen H, Nevalainen T, Sundström J (2006) Biochemical and clinical approaches in evaluating the prognosis of colon cancer. Anticancer Res 26: $4745-4752$

Tavassoli FA, Devilee P (eds) (2003) World Health Organization Classification of Tumours. Pathology and Genetics of Tumours of the Breast and Female genital Organs, p 19, IARC Press: Lyon

Warwick J, Tabar L, Vitak B, Duffy SW (2004) Time-dependent effects on survival in breast carcinoma: results of 20 years of follow-up from the Swedish Two-County Study. Cancer 100: $1331-1336$

Yang YH, Dudoit S, Luu P, Lin DM, Peng V, Ngai J, Speed TP (2002) Normalization for cDNA microarray data: a robust composite method addressing single and multiple slide systematic variation. Nucleic Acids Res 30: e15

Yu R, Ren SG, Horwitz GA, Wang Z, Melmed S (2000) Pituitary tumor transforming gene (PTTG) regulates placental JEG-3 cell division and survival: evidence from live cell imaging. Mol Endocrinol 14: 1137-1146

Zeeberg BR, Feng W, Wang G, Wang MD, Fojo AT, Sunshine M, Narasimhan S, Kane DW, Reinhold WC, Lababidi S, Bussey KJ, Riss J, Barrett JC, Weinstein JN (2003) GoMiner: a resource for biological interpretation of genomic and proteomic data. Genome Biol 4: R28

Zhang X, Horwitz GA, Prezant TR, Valentini A, Nakashima M, Bronstein MD, Melmed S (1999) Structure, expression, and function of human pituitary tumor-transforming gene (PTTG). Mol Endocr 13: 156-166 